\title{
Place based education in the context of waste-related implications on health and welfare among Bedouin Arab communities in the Israeli Negev
}

\author{
O. Ben-Zvi Assaraf, J. Cwike, W. Sedawi \& G. Tsofit \\ Ben-Gurion University of the Negev, Israel
}

\begin{abstract}
Waste and its proper management is a central environmental issue that is currently confronting countries around the world. Uncontrolled waste production and disposal can cause long-term environmental damage to air, water, land, and to the health of humans - most particularly children. Every year, approximately 5.2 million people, including 4 million children, die of waste-related diseases. In Israel, solid urban waste is disposed of primarily in landfills (85\%), but the unrecognized Bedouin settlements in the Negev desert do not have access to regular waste disposal. This forces their residents to try and manage their waste themselves by incineration and other unofficial methods such as dumping and use of refuse pits, practices that are proving hazardous to the community's environment and to its health. Our study is part of an extensive project designed to encourage the use of alternative means of waste disposal and technologies for recycling and generating bio-gas and to provide Bedouin women with the knowledge of this technology along with its health benefits. While an earlier study was focused on the adult patterns and perceptions in dealing with environmental waste, this one focuses on those of the community's children, who are active participants in the disposal of domestic waste, and who are therefore also exposed to its hazards. The goal of this study is to develop an elementary school curriculum to provide students with the knowledge and cognitive skills to cope with environmental hazards that they are exposed to in their local environment with an emphasis on waste.
\end{abstract}

Keywords: waste hazards, health education, place based education. 


\section{Introduction}

\subsection{The Bedouin population of the Negev and the evolution of their waste problem}

The difficulties that the population of the unrecognized Bedouin villages is currently having with waste management can be attributed at least in part to several key - and relatively recent - changes that have occurred in their lifestyle. The Bedouins are an indigenous group of semi-nomadic tribal descendants, who have traditionally dwelt and roamed in the desert areas of the Middle East and North Africa, including the Negev desert. The Negev spans the Southern half of the State of Israel, constituting $58 \%$ of its land mass, but it is relatively sparsely populated, with approximately $10 \%$ of Israel's population residing there While the Bedouins who live in the Negev are Muslims, they are a distinct sub-culture owing to their close ties to the desert landscape and the lifestyle that evolved here. The Bedouins of the Negev now constitute an ethnic minority within the State of Israel, geographically and culturally distinct from other Israeli Arabs and Jew (Levinson and Abu-Saad [1]). Al-Krenawi [2] suggested that their traditional lifestyle was structured around seasonal migration with their herds, with women, children and elders left behind to tend the specific familial territory, and men returning to their designated homes periodically in accordance with the seasons

However, for many Bedouins, this traditional lifestyle has undergone a fundamental change. An increasing proportion (69\%) of the 188,000 Negev Bedouins now live in recognized townships, while approximately $23 \%$ live in unrecognized villages and $8 \%$ live in townships that were recently recognized and given legal status (Cwikel [3]). The unrecognized villages lack basic municipal infrastructure such as electricity, water, sewage, waste management services and roads. Since the unrecognized villages lack official government recognition, these settlements do not receive municipal funds; they have no formal system of local government and pay no taxes. Their status also dictates that all construction in them is illegal, and since all domestic structures are under perpetual risk of being torn down, they tend to be temporary, composed of light substances such as fabric, tin or wood (The Negev Bedouin, Statistical Data Book, \#3, 2010). Because they are not connected to the state's electrical grid, most houses have no refrigerators, the settlements' few public institutions have no electricity and the streets are unlit. More than $80 \%$ of the population derives electricity from private generators that are used only a few hours every day due to the high cost of their operation. Some people use solar energy cells (AlKrenawi [2]). Finally, trash of all types in these settlements is not regularly collected, and therefore often piles up. While there are no definite statistics for waste production in unrecognized settlements, we may assume that the amount is comparable to that generated by permanent Bedouin settlements, which are estimated to generate an approximate 19,000 tons per year (Abu-Bader [4]). Lacking access to organized waste disposal, the residents of these villages must dispose of their waste themselves. The most common method of independent 
disposal is incinerating the waste on a weekly basis - usually in nearby pits or dry riverbeds (Almi [5]). Meallem [6] reported that some villagers burn their waste in barrels only several meters from their homes. Another form of disposal is dumping the trash in open spaces away from the village. While these waste management practices were well suited the traditional, nomadic Bedouin lifestyle, this has recently undergone several key changes that have turned what were once relatively innocuous and effective actions into potential hazards to the villages' environment and to the health of their population.

The first significant shift that has occurred is in the content of the waste that must be managed. For most of the centuries that the Bedouins have spent roaming the desert, nearly all of the waste that they generated would have been organic, and would therefore have caused no damage to the environment if incinerated or left to biodegrade. Meallem [6] claimed that today, however, the Bedouins' live incorporate many of the inorganic substances that are ubiquitous in modern society, and their waste has therefore become primarily nonbiodegradable and potentially far more hazardous. The waste generated by the unrecognized village of Um Batin, for example, is an amalgam of miscellaneous packaging materials, diapers, aerosol containers, paper and cardboard, glass, rope, barrels, buckets, tires etc.

The incineration of these new materials causes air pollution and foul smells that disperse for dozens of kilometers from the source of the fire. This can cause serious health problems, particularly for those who already suffer from respiratory difficulties. The airborne toxins released by the practice of disposing of household waste by burning it in the yard are not only inhaled by the nearby residents, but can also adversely affect village gardens when ash residue falls on plants. Burning waste in open areas can also pollute the ground and water by releasing dangerous materials like leftover pharmaceuticals, cleaning products and medical waste into them. This change in the content of the waste now generated by the Bedouin population only serves to compound the problems created by two additional lifestyle changes: the transition from a primarily nomadic to a primarily sedentary life, and a substantial increase in population due to the availability of modern medical facilities and the resulting drop in child mortality. Whereas once the Bedouins lived in small tribes dispersed throughout the desert and continually moving from place to place, they now live in far denser, sedentary communities. Such increased numbers must necessarily generate waste in far greater amounts, which can no longer be simply left behind to safely decompose.

Waste-related studies of these Bedouin settlements have revealed that their population is subject to constant environmental and health hazards, which originate in the settlements and in their immediate vicinity and which have been linked to difficulties in waste disposal. The rates of hospitalization for infection amongst Bedouin children are high in relation to Jewish children in the Negev area. The most common infectious illnesses are in the respiratory and digestive systems, and are related to living conditions. Meallem [6] found a high rate of respiratory illnesses amongst Bedouin women, explained in part by proximity to 
smoke from waste incineration in the yard, which primarily affects women and children since they spend more time in the vicinity of the settlement.

The residents of the unrecognized villages have expressed a great deal of concern for these environmental hazards, but as yet there is still no organized disposal of waste, and no applied environmental education. Providing these is the ultimate goal of the study presented here, which sought to gather information that would later be put to use in designing an appropriate and relevant environmental education program. Beyond this immediate goal, however, our study is also a subset of a larger project that aims to equip the populations of these villages with the knowledge and the means required to convert their waste into biogas.

\subsection{Biogas: a sustainable solution}

Introducing bio-gas technology to the Bedouin population is an initiative that hopes to attend to several interconnected problems at once. In addition to addressing the hazardous health issues generated by their difficulties in waste management, biogas can also serve as a renewable energy source for a population for which access to reliable energy is a problem. Finally, it can be employed as a source of additional revenue and as a catalyst towards community development.

The introduction of biogas digesters in Bedouin unrecognized villages can potentially impact their community in several beneficial ways. Due to the lack of infrastructure, energy is scarce and locally produced. Most Bedouin households rely on electric generators, solar energy, gas, and wood. The high cost of these solutions does not allow sufficient or continuous electric supply, and can result in adverse health outcomes such as increased respiratory and urinary tract infections (Cwikel and Barak [7]). Rural Bedouins still raise goats and sheep, yet they lack an organized way to handle the livestock waste. Waste products are usually accumulated and eventually burned or dumped resulting in additional health hazards. These excretions can serve to feed biogas digesters, and provide gas for cooking, refrigeration and electric generators. The biogas digesters byproducts (slurry) can be used as agricultural fertilizer. Meallem's study and our experience working with the Bedouin community reveal that some families do not have refrigerators, whereas other families run electricity only for a few hours a day, and move food from the refrigerator to the freezer in attempt to maximize refrigeration when electric supply is not available. Thus utilizing biogas for refrigeration will promote better nutrition based on foods that are refrigerated. Other families, cooking on wood or purchasing gas canisters, can utilize biogas for cooking and will reap both health and financial benefits from biogas production.

The biogas technology has so far been introduced into two unrecognized villages in a process of participatory technology development. This type of research aims to produce change and solve social problems by forging a collaboration between researchers, community workers and community residents. Researchers and community members thus work together to explore and understand the issues at stake, taking mutual responsibility for the research 
process. Diop and Laban [8] coined the term "participatory technology development (PTD)“ to describe a method of participatory research related to technology -a process that involves people in analyzing their own current problems and in seeking solutions that lead to the testing of an innovation. In their study PTD was successfully implemented with Egyptian women regarding environmental and health issues related to livestock and waste disposal.

The ultimate goal of the project is to build a model for community development related to waste management in communities that lack infrastructure and municipal services for waste management. This model will target communities of indigenous origin that lack the socialization and infrastructure for handling modern waste and acknowledging its hazards. If found applicable, the model can be expanded to include the over 100,000 Bedouin inhabitants, who currently suffer from lack of infrastructure and practice hazardous waste management.

For a PAR/PTD project to succeed, trust and commitment are required of everyone involved in the project (Diop and Laban [8]). It is therefore extremely important that any action taken should be based in the actual needs and desires of the population that it will ultimately impact. For this reason, it is important to understand how waste and its management are currently experienced by all members of this community, so that any action that is undertaken takes the specific nature of these experiences into account. While studies have so far been conducted to determine the attitudes and perceptions of adults towards waste, its management and its impact, they have not yet addressed these issues among the settlements' children, despite the fact that children take an active part in their community's waste management, and are also exposed to its hazards.

The children of the unrecognized Bedouin settlements are not peripheral to their community's changing experience with waste. Malandrakis [9] found that these children participate actively in the community's current waste management practices, and they have been reported injured while handling waste, sustaining burns or suffering from respiratory illnesses as a result of waste mismanagement. It is therefore crucial that both parents and their children understand the dangers involved, if future harm to their health and environment is to be prevented (Furthermore, children's attitudes can play a direct role in solving environmental problems, since they can exert intergenerational influence on the knowledge, attitudes and behavior of adults (parents, teachers, local community), and thus function as motivators for environmental change in their families and close community (Gallagher et al. [10]). The study presented here was conducted in preparation for the introduction of biogas facilities into two more unrecognized villages, and was designed to lay the groundwork for an advance program in environmental education by exploring the current waste-related knowledge, attitudes and behaviors of these villages' children.

\section{A child's-eye view: knowledge, attitudes and behavior}

In 2003, sustainable development (SD) was formally recognized as a national policy in Israel, to be implemented by all Ministries. As part of their new SD 
policy, the Ministry of the Environment began a campaign in November 2011 to solve the problem of private waste incineration in the Arab population. A central factor in this campaign was education towards the development of environmental literacy.

The goal of this study is to develop an elementary school curriculum to provide students with the knowledge and cognitive skills to cope with environmental hazards that they are exposed to in their local environment with an emphasis on waste. The study is based on observations collected in preliminary research on the manner in which $4^{\text {th }}$ and $5^{\text {th }}$-grade students living in unrecognized Bedouin settlements in the Negev perceive the topic of waste, and its effects on health and the environment. Based on the results of this research, we are currently working with the scientific advisor from the Ministry of Education in the area of science education to develop a pilot program, which will be tested in two unrecognized villages and ultimately developed into recommendations for a more comprehensive, and formal, curriculum. This study sought to characterize the perceptions of primary school students from unrecognized Bedouin settlements towards waste and its influence on health and the environment.

\subsection{Research sample and tools}

The study included 30 students, 16 boys and 14 girls, in grades four ( $n=13)$ and five $(n=17)$ (ages 8-10). All of them live in one of two unrecognized settlements in Israel's Negev area, which we will name here only as Village A and Village B. The students who live in Village A go to school in a nearby recognized Bedouin town, since Village A has no school. The students have organized transportation for the 15 minute drive to and from school. They also participate in an after-school club in their own village every Wednesday, Thursday and Friday afternoon. The other students live and study in Village B. All of the children come from low socio-economic backgrounds.

Data for this study was collected using three qualitative research tools drawings, in-depth semi-structured interviews, and observations.

Drawings - We used drawings to examine the children's immediate perception of the environment in which they live and of waste as part of that environment. The children were given A4 sized paper to draw on, and asked to make two drawings - "my village" and "waste in my village" - and explain what they drew. Drawing time was between 20 and 40 minutes. When they were done, the researcher asked them questions about what they had drawn and recorded their answers.

Interview - The interview consisted of 30 questions. They covered topics like the meaning of waste, waste management methods, the garbage dump and its place, types of waste in the dump, animals affected by the dump, the dump's impact on the children's lives, incineration, frequency of incineration, opinions about incineration, distance of incineration sites from their houses, waste-related illnesses, awareness of urban waste management methods, hazardous materials and how to handle them, reuse of waste materials, and reduction of waste. 


\subsection{Results from preliminary study}

Data was collected by a combination of three qualitative tools - interviews, illustrations and observations from Bedouin students from unrecognized villages in $4^{\text {th }}-5^{\text {th }}$ grades. These allowed us a glimpse of the students' worlds, and the kinds of elements that influence their perceptions. The results were divided into the 3 main categories that the eventual science education curriculum would be based on, examining students' perceptions through the three central components of environmental literacy: knowledge, affect and behavior.

Analysis of the children's knowledge showed that it tended to be overwhelmingly based on personal experience, with very little of their knowledge being attributed to what they had learned in school. They were therefore largely uninformed about environmental conservation (e.g. perceived tossing waste in the river as an efficient method of disposal), health preservation (incineration is a good cleaning practice), animal welfare (goats eat plastic bags), how waste breaks down (it melts in the sun), hazardous materials (not realizing batteries release dangerous materials) and urban waste management. This indicates a lacuna in their cognitive understanding on the topics of health and environment.

Second, the children's attitudes towards waste and its impact were ambiguous. On the one hand, their interviews included declarations of environmental responsibility, but on the other their explanations also revealed a lack of care towards environmental preservation. They also expressed a variety of emotions: fear and concern over incineration and its hazards, sorrow over harming animals, awareness of the 'fun' to be derived from playing with and selling objects from the trash, indifference towards responsibility, discomfort arising from the unpleasant smell, anger and shame over being dirty in front of others.

The ambiguity can be seen, for instance, in the two illustrations below. It is clear from both illustrations that the children perceive waste as an integral part of their environment, intimately associated both with their homes and with themselves. The child who drew the one on the left explained, "I drew a house, a trash can, fire and smoke, children playing in the yard are bothered by the smoke." The size of the smoking trash can, nearly as big as the house itself, emphasizes the strength of the waste's presence in the child's perception of his environment. Waste looms large in the right-hand picture too, which is captioned, "I drew a house, trash around the house, a goat farm, children playing in the trash". Here the house is surrounded by mounds of trash, with another mound placed prominently in the foreground with the children playing on it. The picture on the left emphasizes the overwhelming presence of waste as a negative element in the child's environment, but the one on the right also recalls the positive connotations of the rubbish dump as a playground and a place where one can find interesting objects that can be turned into toys.

Third, the children's explanations revealed several waste-related everyday behaviors: going to the valley to dump waste, burning or playing with it, making toys from discarded objects like cans and packaging for hazardous materials. They also gather metals, batteries, and bottles for sale to help provide for their 

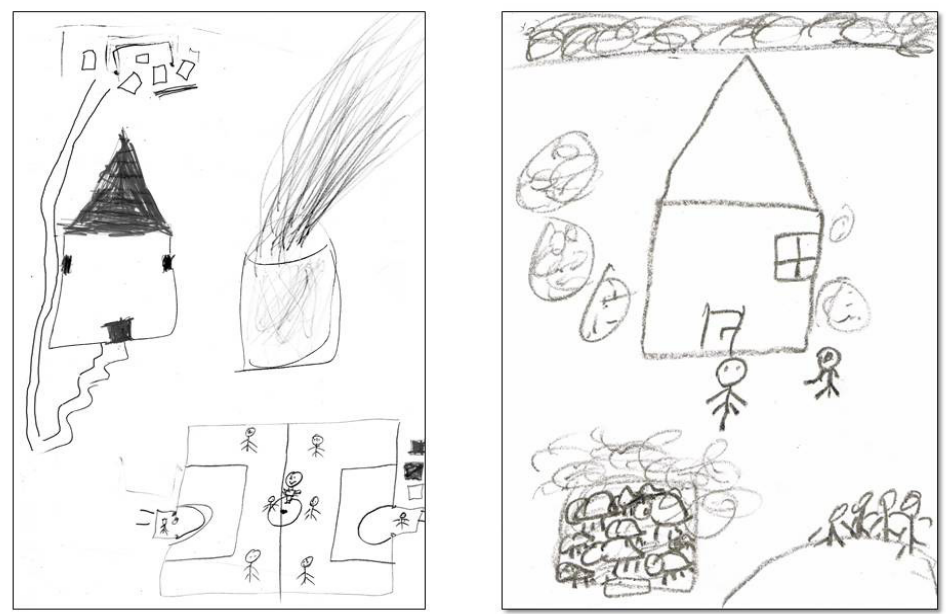

Figure 1: $\quad$ Student`s drawings showing waste as part of his environment.

families. Their daily contact with waste materials exposes these children to health hazards from broken waste fragments, toxic chemicals, smoke inhalation and burning trash piles. Waste also affects the community as a source of conflict between neighbors who are disturbed by the proximity of one another's waste, its odor and the smoke from its incineration. These results indicate that the waste problem in these unrecognized Bedouin settlements is complex, influencing their environment, community and health. Cwikel [3] claimed that any solution to this problem must include an educational intervention program that fosters behavioral change - an epidemiological-social challenge.

\subsection{The "Waste and My Health" learning unit}

The following learning unit is based on the results of the study described above, and on the insights they provided into the students' perceptions of waste, the elements that influence these perceptions and the ways in which the waste problem is currently being managed in the students' daily lives. It was designed to raise the awareness of fourth grade students from the unrecognized Bedouin villages in the Negev desert to the topic of waste and its impact on the environment and on human health. The unit stresses that improper waste management (such as unsupervised incineration) is a real hazard to public health, and to the existence of the animals living nearby. This awareness is extremely important as a key step towards behavioral change that will keep these students from further environmental and personal harm.

Following Phillips [11], the learning in this study unit is based on the constructivist approach, in which meaningful learning is generated by the active participation of the student, who must be active, social and creative. The job of the teacher and the learning materials is therefore to guide the student as much as possible towards active engagement with the information. This means that the 
students are positioned in the center of the learning process, and that the primary role of the teacher is to transfer the responsibility of learning to them. In this context, the unit relies on processes of independent inquiry in a range of learning environments: the two field trips, experiments, the observation and examination of what happens in the students' daily lives. Learning and assessment will also be based on a range of independent projects, such as field reports, reports on observations and photographic evidence.

The study unit is composed of 15 in-class study hours and two field trips (one a survey of the local environment and the other a trip to Israel's primary landfill, which is a center of environmental education), and divided into seven chapters (see Table 1 below). Goldman et al. [12] suggested organizing around the three central elements of environmental education: knowledge, attitudes and behavior. Each of these three elements contributes greatly to the individual's eventual environmental activity, which can manifest as anything from small changes in the way that particular individual chooses to behave, to intensive participation in group environmental activities.

Table 1: $\quad$ The study unit: divided by elements of environmental literacy.

Feelings and attitudes
a) What happens to the pile of trash near my house?
Photographing and tracking the fate of trash in my environment.
b) How do I feel when I see waste in my close environment? Drawings and
flashcards to present attitudes towards waste (feeling, opinions, attitudes)
Knowledge
c) What characterizes the waste in my close environment?
Survey of close environment and its components as perceived by students
(hazardous/not hazardous), compared to formal scientific definitions.
d) How does waste affect my health?
Identifying incineration's effects on the skin and respiratory system,
infiltration of toxins, smells, burns, injuries and allergies.
e) How does waste affect the environment?
Photographing evidence: what happens to waste after in rains in the riverbed?;
Getting to know the wild animals in my environment - workshop with guide
from national wildlife foundation: tracking the behavior of local animals
Behavior
f) How should I behave towards the waste in my close environment?
Field trip to village where biogas project has begun; Field trip to the
national center for Integrated waste management, including supervised
incineration and composting.
g) How should we protect ourselves? First aid workshop; Making posters
for awareness campaign
h) What can I do for my close environment?
First aid workshop; making vessels for feeding animals so they do not
approach and eat the waste; home recycling corner (collecting batteries and
bringing to school.


The three elements were designed to represent different types of activity and make possible the assessment of varying levels of involvement]. The beginning of the unit stresses the students' attitudes, which refers to the students' opinions and their desire to take action that will prevent and repair environmental and health problems caused by waste. The second element emphasized in the unit is the students' knowledge and awareness, which enriches the students' knowledge of ecological principles, working on their ability to identify, analyze, investigate and assess problems caused by waste. The third element emphasized is behavior, which addresses the belief in the students' personal and collective capacity to influence the outcome of the waste problem.

Learning in the unit is driven by a succession of authentic socio-scientific questions that relate to the students' physical and social environment (see Table 1 above). This authentic learning environment is a central pedagogical component in the learning process. It serves as a means for: a) constructing abstract concepts in a learning process that moves gradually in a spiral model from the concrete to the abstract; b) adding interest, curiosity and motivation to the learning process, and c) creating a connection to the physical environment $-\mathrm{a}$ place identity. In this sense, the unit is an example of place-based education, an approach in which the content and the pedagogy of the learning process are infused with the physical attributes and the cultural, historic, and socioeconomic meanings of particular places, and in which students regularly work in the local outdoor environment or in the community (Sobel [13]; Hutchison [14]).

The authentic, place-based questions help the students move from chapter to chapter or topic to topic, and guide them on the path to understanding waste's impact on health and the environment. The questions we chose are specifically relevant to these particular students, and thus encourage then to be involved in the learning process. In addition to focusing the students' learning around a particular place, the series of related questions function as an explanatory story. We draw on Millar and Osborne's [15] explanatory story approach, where learning material from different disciplines is presented in narrative form with one uniting central theme. This enables students to relate scientific principles and every-day phenomena and experiences in a coherent manner, thereby constructing a unified and connected body ofknowledge.Table1 details an exemplar series of authentic questions around which the study unit is built, indicating how these are divided according to category and according to the elements of environmental literacy. In framing the questions, and in designing the activities that will be used to answer them, we have endeavored to address the particular needs and circumstances indicated by our investigation of the role that waste plays in these children's lives. It is our hope that our study unit will play its part in helping this very real and pressing problem move successfully towards a resolution.

\section{References}

[1] Levinson, E., and Abu-Saad, A., Statistical yearbook of the Negev Bedouin. Beer Sheva: Negev Center for Regional Development and the Center for 
Bedouin Studies and Development, Ben Gurion University of the Negev Israel. 2004.

[2] Al-Krenawi, A., Awareness and Utilization of Social, Health/Mental Services among Bedouin-Arab Women, Differentiated by Type of Residence and Type of Marriage. Beersheba: The Center for Bedouin Studies and development; The Spitzer Department for Social Work, Ben Gurion University. 2004.

[3] Cwikel, J., Social epidemiology: Strategies for public health activism. New York: Columbia University Press, 2006.

[4] Abu-Bader, S. (ed.).The Negev Bedouin - Statistical Data Book - \#3, 2010. Beer-Sheva, Israel: The Robert H. Arnow Center for Bedouin Studies and Development, Ben Gurion University of the Negev.2011.

[5] Almi, O., "No Mans Land - Health in the Unrecognized Villages in the Negev. Beer Sheva”. Physicians For Human Rights - The Regional Council for Palestinian Bedouin Unrecognized Negev Villages.2003.

[6] Meallem, I., The Management of Solid Waste in Recognized and Unrecognized Bedouin Villages of the Negev: Social Context, Impacts and Recommendations, (M.A), Ben-Gurion University of the Negev.2006.

[7] Cwikel, J. and Barak, N., The Health and Welfare of Bedouin Arab Women in the Negev. Beer Sheva, Israel: Center for Women's Health Studies and Promotion, The Center for Bedouin Studies and Development, The Negev Center for Regional Development, 2003.

[8] Diop J.M. and Laban P., Experiences with Farmer Experimental Design Workshops in Egypt. Participatory Technology Development Working Paper 1. ETC Ecoculture Netherlands, 2000.

[9] Malandrakis, G. N., Children's understandings related to hazardous household items and waste, Environmental Education Research, 14(5), 579601, 2008.

[10] Gallagher, J., Wheeler, C., McDonough, M. and Namfa, B., Sustainable environmental education for a sustainable environment: Lessons from Thailand for other nations. Water, Air and Soil Pollution, 123(1-4), 489503, 2000.

[11] Philips, D. C., The good, the bad and the ugly: The many faces of constructivism. Educational Researcher, 24 (7), 5-12.1995.

[12] Goldman, D., Ben-Zvi-Assaraf, O., and. Sharabani, D., The Effects of an Informal Environmental Training Program on Junior High School Students Environmental Literacy. International Journal of Science Education, 2012.

[13] Sobel, D., Place-based education: Connecting classrooms and communities. Great Barrington, MA: Orion, 2003.

[14] Hutchison, D., A natural history of place in education. New York, NY: Teachers College Press, 2004.

[15] Millar, R., and Osborne, J., Beyond 2000: Science education for the future. London: Kings College, University of London, 1998. 